\title{
STREET LIGHT CONTROLLER WITH GSM TECHNOLOGY
}

\author{
H. P. Khandagale \\ CSE, Assistant Professor, \\ Department of Technology, Shivaji University, Kolhapur, 416004 \\ R. Zambare, P. Pawar, P. Jadhav, P. Patil, S. Mule \\ Student, B.Tech, CSE Dept, Department of Technology, \\ Shivaji University, Kolhapur, 416004
}

\begin{abstract}
The latest trend in the technologies related to wireless communication has led to the emergence of several engineering designs for human requirements. The creeping interests in the wireless and GSM based projects, we came up with this idea of developing a simpler, multipurpose, costeffective design to control the on-off street lights via short message service (SMS). Commands are sent to street light for night lighting Applications system through user' mobile as data through SMS (Short Service Messages) providing a cost effective, reliable far reaching access to the user. The coded SMS is sent to the light relay system to base station controller that receives the messages, decodes the messages, initiates required automation operations and responds to the successful initiations by a reply to the user.
\end{abstract}

Key Words: micro-controller, IOT, sensors, GSM

\section{INTRODUCTION}

Street light controllers are smarter versions of the mechanical or electronic timers previously used for street light ON-OFF operation. They come with energy conservation options like twilight saving, staggering or dimming. Also many street light controllers come with an astronomical clock for a particular location or a Global Positioning System (GPS) connection to give the best $\mathrm{ON}$ - OFF time and energy saving.

Automatic Street Light Control System is a simple and powerful concept, which uses transistor as a switch to switch ON and OFF the street light automatically. By using this system manual works are removed. It automatically switches ON lights when the sunlight goes below the visible region of our eyes. It automatically switches OFF lights under illumination by sunlight. This is done by a sensor called Light Dependant Resistor (LDR) which senses the light actually like our eyes.

By using this system energy consumption is also reduced because now-a-days the manually operated street lights are not switched off properly even the sunlight comes and also not switched on earlier before sunset. In sunny and rainy days, ON time and OFF time differ significantly which is one of the major disadvantage of using timer circuits or manual. This project exploits the working of a transistor in saturation region and cutoff region to switch $\mathrm{ON}$ and switch OFF the lights at appropriate time with the help of an electromagnetically operated switch.
A street light, lamppost, street lamp, light standard, or lamp standard is a raised source of light on the edge of a road or walkway, which is turned on or lit at a certain time every night. Modern lamps may also have light-sensitive photocells to

turn them on at dusk, off at dawn, or activate automatically in dark weather. In older lighting this function would have been performed with the aid of a solar dial. It is not uncommon for street lights to be on poles which have wires strung between them, or mounted on utility poles.

This project exploits the working of a transistor in saturation region and cut-off region to switch $\mathrm{ON}$ and switch $\mathrm{OFF}$ the lights at appropriate time with the help of an electromagnetically operated switch. Automatic Streetlight needs no manual operation of switching ON and OFF. The system itself detects whether there is need for light or not. When darkness rises to a certain value.

\section{Choice of the topic with reasoning}

GSM based street light automation is basically used to control street light automatic by the help of GSM module (global system for mobile communication).It is designed to performing $\&$ increase the efficiency of street light even more during in nights. . It consists of an 89C51 microcontroller which on setting of time delays switches ON/OFF the street lights and sends the update through a phone to the specified phone number. This is the best way of managing a street light system. There are two modules client server \& server side. The client server consists of GSM module which is connected to the microcontroller. The server side consists of web server; it has a core engine which interacts with the user, database and the GSM communication manager. By applying the proposed system, streets can be illuminated with lower power consumption lamps, low operating cost, and low $\mathrm{CO} 2$ emissions and environmentally friendly. it is best used without any disadvantage as compared to other.

Industry of street lighting systems are growing rapidly and going to complex with rapid growth of industry and cities. Automation, Power consumption and Cost Effectiveness are the important considerations in the present field of electronics and electrical related technologies. To control and maintain complex street lighting system more economically, various street light control systems are developed. These systems are 
developed to control and reduce energy consumption of a town's public lighting system using different technologies. The existing work is use the High intensity discharge lamp (HID). HID presently used for urban street light are based on principle of gas discharge, thus the intensity is not been controllable by any voltage reduction method as the discharge path is broken.

\section{LITERATURE REVIEW}

In the Existing system we find many types of street lights where the power consumption is not efficient and the intensity of light is not magnified when there is fog, rain and rainfall. Literature review is an assignment of previous task done by some authors and collection of information or data from research papers published in journals to progress our task. It is a way through which we can find new ideas, concept. There are lot of literatures published before on the same task; some papers are taken into consideration from which idea of the project is taken.

B. K. Subramanyam1 et al. [2], worked on intelligent wireless street light control and monitoring system, which integrates new technologies, offering ease of maintenance and energy savings. Using solar panel at the lamp post By using LDR it is possible to save some more power and energy, and also we can monitored and controlled the street lights using GUI application, which shows the status of the lights in street or highway lighting systems.

Anila Devi Y et al.[3], worked on GSM Based Remote Control System of High Efficiency Intelligent Street Lighting System Using A Zigbee Network of Devices and Sensor. New intelligent and smart street light system is designed with wireless technology for maintenance and network of sensors for controlling. In which, they used high efficiency LED lamp which consumes less energy with high life time and which are supplied with renewable energy of solar panels.

R. Angeline et al. [4] The data from the Bio sensor, Gas sensor, Smoke sensor, Sound sensor, And PWM dimming is sent to the micro controller which controls the recording or it intimidates the information and the data is sent to GSM module which maneuvers the street lamping system the main work ofthe system is to get the information or record the information and send the same to the main server.

M. Shariz Ansari et al. [5] It consists of an 89C51 microcontroller which on setting of time delays switches ON/OFF the street lights and sends the update through a phone to the specified phone number. This is the best way of managing a street light system. There are two modules client server \& server side. The client server consists of GSM module which is connected to the microcontroller. The server side consists of web server; it has a core engine which interacts with the user, database and the GSM communication manager. By applying the proposed system, streets can be illuminated with lower power consumption lamps, low operating cost, and low $\mathrm{CO} 2$ emissions and environmentally friendly.

B.Abinaya, S.Gurupriya, M.Pooja et al. [6]. Their system is mainly used for smart and weather adaptive lighting in street lights. The project is implemented with smart embedded system that controls the street light based on detection of sunlight. During the night time the street light gets automatically OFF. The ON/OFF can be accessed anywhere anytime through internet. A camera is placed on top of the street light to track the actions performed on the road where the foot-ages are stored in a server. In addition to this, a panic button is placed on the pole, in-case of any emergency or danger, the person in danger can press this button which raises an alarm at the nearby police station. Whenever the panic button is pressed, the footage at that time recorded by the camera is sent directly to the cloud account. The access of the account is given to the particular police station by which they can view the incident's spot. The manual operation using GSM technology is completely eliminated. Thus the system is mainly designed to ensure safety and to prevent energy wastage.

Veena P C, Paulsy Tharakan, Hima Haridas, Ramya K, Riya Joju, Ms. Jyothis T et al. [7].Their article presents road light framework, the idea to support vitality effectiveness of a city. These days, individuals are excessively occupied, and unfit, making it impossible to discover time even to turn OFF the lights at whatever point not required. The framework works like, the road lights are changed to $\mathrm{ON}$ state in the night prior to the sun sets and they are turned OFF following day morning after there is sufficient light on the streets. This paper gives a standout amongst other answer for diminishing the vitality utilization. This framework identify vehicle development/human nearness on express ways to switch ON just a piece of road lights in front of it and to turn OFF the trailing lights keeping in mind the end goal to diminish utilization of vitality.

Prof. V. K. Bhangdiya et al. [8].In this paper, they have proposed low power consumption LED Street light based on smart control system. In this system we used sensor to measure sun light intensity, day / night condition and traffic on a road. The intensity of LED Street light varies with these parameters. They have used two sensors that are LDR (light depending resistor) sensor and motion sensor. LDR sensor is used to control the switching action of LED street lights depending on sunlight condition. Motion sensor is used to change the intensity of LED light, when there is no motion of object at mid night on street then all the street lights are dimmed, to reduce the power consumption. In this paper proposed state of art system which consists of PIC 18F4550 micro controller, LDR sensor, motion sensor, LED driver and Computer.

Thinaharan Ramachandran,Vasaki Ponnusamy et al. [9]. The proposal here is to design a smart street light system (SSL) which uses solar power supply to operate the controller, the communication module and to charge storage battery during day time. The charged battery will be used to operate at night. Therefore the system is independent from electric power source. An automation control is required to establish the functions of this system. The software at 


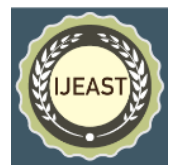

remote server is used for logging the light intensity obtained from the lamppost via the ZigBee module. The bidirectional communication established between the remote server and the lamppost enables the maintenance effectiveness of the smart street light. The RMI will ease the maintenance process of the smart street light over remote monitoring. The system can be improved with employing an image processing method to extract image for evaluation purposes.

\section{PROPOSED SYSTEM}

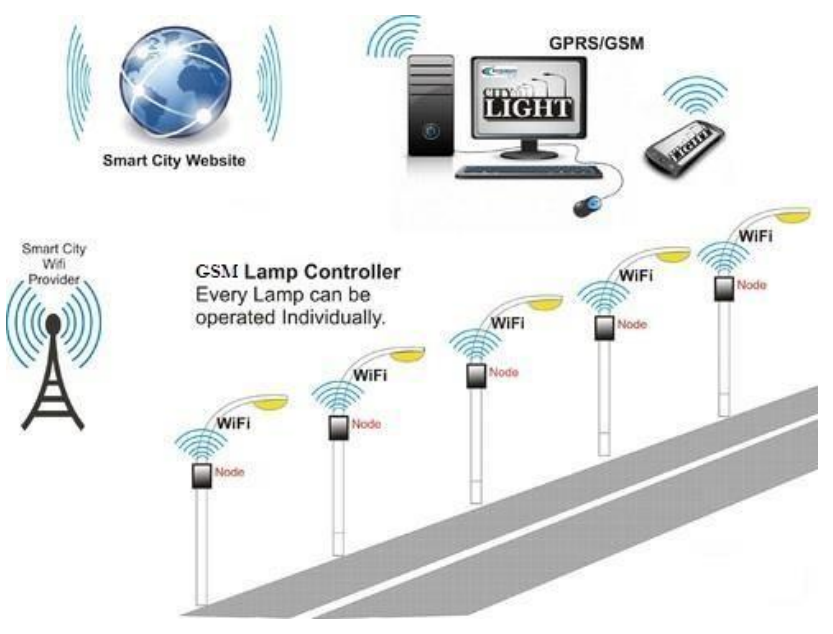

Fig 1. Street light controller with wireless technology

Thus message is decide whether the street light should ON/OFF by the help of gsm and microcontroller circuit It enables regulate their communication strategies according to dynamically changing network environment. Street lights should work on the systematic manner by the help of circuit and huge reduction in power consumption on whole around the world it is -less costly and effective in manner it should reduce the time wastage of human effort and control from one place or any common panel. Provide the better efficiency to do work.

\section{Here is our plan:}

By sending a SMS to microcontroller circuit by the help of GSM circuit through mobile the unit of street light automatically switch ON/OFF. LED should indicate whether the street light is on or off and they should be control by using fix timer. Therefore wastage of time and requirement of skilled worker is reduced to a great extent. We can monitor and control more parameters and devices. We used in various rooms like seminar hall, conference room, and study rooms in college where the capacity of room is limited and should not be exceeded. So the project will display the actual number of street light is work.

\section{THE METHODOLOGY COMPRISING}

\section{Methods of data collection: -}

Hardware implementation of Auto light intensity and Auto switching system control for Smart Street lighting system is proposed. We used AT COMMAND for functionally of street light just like server used. By sending a SMS onto microcontroller by the help of mobile they read it and match by itself if microcontroller are accept them then, street light is ON vice versa for OFF we are used contractor against to relay to protect and control of maintained of supply. There is inbuilt circuit are here power supply are given to module therefore by the help of ac capacitor we reduce the ripple and then convert into dc by the help of bridge rectifier further by using antenna they transmit the MSG to micro controller the read and accept if they match with at command after then MSG should be received led light emitted and unit of street light 1 or unit 2 or unit 3.all of them should be open. Vice versa they should be OFF. In this diagram we are using this type of methodology

\section{Methods of data analysis: -}

Our system maneuvering of street lamp using GSM technology is divided into three modules based on its functionality

- Street lamp switching on and off

- Sensor module

- $\quad$ GSM module for maneuvering

\section{Street lamp switching on and off:}

- The solar energy that is energized and stored in the storage area is being used if and only if it is in use.

- The switching on and off is taken care by the automated structure that is been programmed using the ardiuno with the help of the IR sensor.

\section{Sensor module:}

- the sensor module which is integrated with 2 sensors in it and those are: IR sensor and LDR.

\section{GSM Module:}

- This module is the main hub of the project which maneuverers the street lamping system.

- The main work of this module is to get the information or record the information and send the same to the main server. The module is on the whole collaborated with a micro controller which controls the recording or intimidating the information. 


\section{SYSTEM ARCHITECTURE}

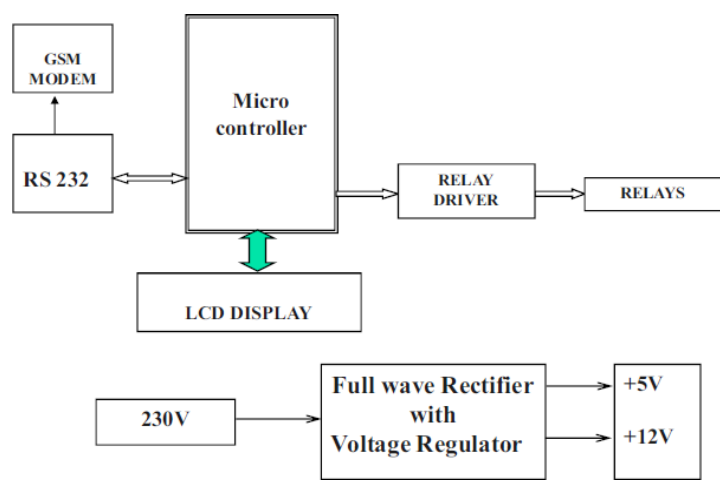

Fig . 2 functional block diagram

The entire street light lamps are connected to relay driver circuit. Base server will run a Java application which will maintain complete street when we want to switch ON/OFF any particular street light, server will send a GSM SMS to that street controller to take necessary action. Further, with By using the auto switching system of Smart Street light we can also reduce energy consumption because manually operating lighting system are not switched ON earlier before sunset and also not switched OFF properly after the sun rise. In healthy condition street light operates in a normal working condition by turning ON and OFF automatically for night and day light, but in unhealthy condition the street light does not turn ON or OFF and it sends a feedback message to control room to notify the host. The host is able to turn ON or OFF the street light manually and wirelessly with the help of graphical user interface. In a fault condition, the street light sends an Error message to the control room to alert the host or operator regarding the fault. The operator Notified and takes further action to carry out repair works. As compared to the conventional street lighting system, the smart street system offers high reliability, low maintenance. The feedback system allows the street light to respond with the control room reporting its daily status and condition Mobile should not only used for MSG but also for web application.

\section{CONCLUSION}

From this project we conclude that this is a system which is need of implementation for our country especially because the street lamps are not maneuvered properly by the management. This project isn't the one which has not even come but some advancement we have made and have done the project. This project also has much advancement which can be tried in the future scope.

\section{ACKNOWLEDGEMENT}

We express our sincere thanks to our project guide and Prof. who always being with presence \& constant, constructive criticism to made this paper. We would also like to thank all the staff of computer department for their valuable guidance, suggestion and support through the project work, who has given co-operation for the project with personal attention.

Above all I express our deepest gratitude to all of them for their kind-hearted support which helped us a lot during project work. At the last I thank my friends, colleagues for the inspirational support provided to me through a project work.

\section{REFERENCES}

1. Intelligentsystem for monitoring andcontrolling of street lightusing the GSMtechnology, International conference on information processing, December 1619, 2015, by Swati rajes Parekar, prof ManojM. Dongre.

2. B. K. Subramanyam, K. Bhaskar Reddy, P. Ajay Kumar Reddy, "Design and Development of Intelligent Wireless Street Light Control and Monitoring System Along With GUI", International Journal of Engineering Research and Applications (IJERA)Vol. 3, Issue 4, Jul- Aug 2013, pp.21152119.

3. Anila Devi Y, V. Jaya Prakash, "GSM Based Remote Control System of High Efficiency Intelligent Street Lighting System Using A Zigbee Network of Devices and Sensor" International Journal of Science and Research (IJSR) P.P 23197064.

4. R. Angeline, B. Gokul, B. Prashanth, P. Hareesh, Animesh Singh "Monitoring and Controlling of Street Lamp using GSM Technology", International Research Journal of Engineering and Technology (IRJET) Oct 2018.

5. M. Shariz Ansari, Tanmay Srivastava, Rishabh Saxena, Saurabh Singh "GSM Based Street Light Automation" International Journal of Advanced Research in Electrical, Electronics and Instrumentation Engineering (An ISO 3297: 2007 Certified Organization) Vol. 4, Issue 5, May 2015

6. B.Abinaya, S.Gurupriya, M.Pooja "IOT BASED SMART AND ADAPTIVE LIGHTING IN STREET LIGHTS "2017 Second International Conference On Computing and Communications Technologies(ICCCT $\left.{ }^{\mathrm{ec}} 17\right)$

7. Veena P C, Paulsy Tharakan, Hima Haridas, Ramya K, Riya Joju, Ms. Jyothis T S "Smart Street Light System based on Image Processing"2016 International Conference on Circuit, Power and Computing Technologies [ICCPCT]

8. Prof. V. K. Bhangdiya "Low Power Consumption of LED Street Light Based on Smart Control System"2016 International Conference on Global Trends in Signal Processing, Information Computing and Communication

9. Thinaharan Ramachandran,Vasaki Ponnusamy, Low Tang Jung, Anang Hudaya "ZigBee Wireless Communication for Monitoring Renewable Street Light System "2014 IEEE Journal. 